\title{
Cartografia geotecnogênica da região do Cabuçu, Guarulhos, São Paulo, Brasil
}

\author{
Geotechnogenic cartography of Cabuçu region, Guarulhos city, São \\ Paulo, Brazil
}

\author{
Daniele dos Santos Marques $^{\text {ab }}$, Antonio Manoel dos Santos Oliveira ${ }^{\text {ac }}$ \\ ${ }^{\mathrm{a}}$ Universidade Guarulhos, Universidade Guarulhos \\ daniele.santos.marques@gmail.com, caoliveira@prof.ung.br
}

\section{RESUMO}

O processo de transformação das paisagens naturais em culturais ou tecnogênicas vem exigindo novas abordagens e mapeamentos dos novos terrenos e depósitos produzidos pelo homem. Há ainda poucos exemplos de cartografia geotecnogênica no país e este trabalho busca apresentar um exemplo que possa contribuir para o desenvolvimento do tema. A cartografia elaborada para a região do Cabuçu em Guarulhos (SP) foi fundamentada no estudo do uso da terra local, sua evolução e nas classificações disponíveis de terrenos e depósitos tecnogênicos.
\end{abstract}

Palavras-chave: Tecnógeno; Depósitos tecnogênicos; Abordagem geotecnogênica; Cabuçu; Guarulhos.

\begin{abstract}
The process of transformation of natural landscapes into cultural or techogenic ones has required new approaches and mapping of the new land and man-made deposits. There are still few examples of geotechonogenic cartography in Brazil and this study aims to present an example that may contribute to the development of this issue. The mapping elaborated for Cabuçu in Guarulhos city, São Paulo state, was based on the study of local soil use, its evolution, and the available classifications of artificial land and techogenic deposits.
\end{abstract}

Keywords: Technogene; Technogenic deposits; Geotechonogenic approach; Cabuçu; Guarulhos.

\section{Introdução}

A abordagem geotecnogênica tem como um de seus principais desafios o mapeamento das coberturas tecnogênicas que se superpõem aos terrenos naturais, alterados ou não por escavações ou contaminações. Entretanto, as pesquisas sobre as formas de representação destes elementos ainda são escassas no Brasil, sendo um exemplo os trabalhos de Mirandola (2003), em áreas de risco da favela Real Parque em São Paulo, e de Silva (2013), para a ilha de Santa Catarina.

O objetivo deste trabalho é apresentar a história da ocupação e as decorrentes alterações geoambientais na região do Cabuçu, Guarulhos (SP), sob o ponto de vista do homem como agente geológico, ou seja, utilizandose de uma abordagem geotecnogênica (Oliveira1990).

\section{Fundamentos}

Para uma maior compreensão das transformações ambientais, faz-se necessária uma abordagem geotecnogênica do uso da terra, conforme proposta de Oliveira (1990, 1995) para a Geologia de Engenharia considerar os problemas geológico-geotécnicos do ponto de vista da ação do homem como agente geológico, com base em Ter-Stepanian (1988).
O tema é relativamente pouco difundido no Brasil, tendo sido realizado, em 2005, o $1^{\circ}$ Encontro Brasileiro do Tecnógeno, pela Associação Brasileira de Estudos do Quaternário (Abequa), na cidade de Guarapari, estado do Espírito Santo (Oliveira 2005).

A Geologia mostra que a superfície terrestre é transformada ao longo das eras pela ação de agentes geológicos externos ou exógenos, como a chuva, o vento e o gelo, e internos ou endógenos, como os terremotos e o vulcanismo. Atualmente, tem sido destacado o papel dos organismos nos processos de alteração da superfície terrestre, a ponto de ter sido construída a Teoria Gaia, que considera o planeta Terra como um ser vivo (Lovelock 1988).

Entretanto, o homem, como espécie, ultrapassou o papel de agente geológico natural manifestando-se como agente cultural da transformação ambiental quando, segundo Ter-Stepanian (1988), passou de coletor e/ou caçador a produtor de alimentos há 10.000 anos, na revolução agrícola. Diferenciando-se dos outros animais, assumiu o papel específico de agente cultural de transformação do meio ambiente, iniciando assim o processo civilizatório (Ribeiro 1975). 
Com base nesta análise, Ter-Stepanian (1988) propõe que a época geológica Holoceno seja considerada uma transição para o Tecnógeno, quando não existirem mais paisagens naturais no planeta, senão em Unidades de Conservação.

Outros autores também consideram o homem como agente geológico, embora possam discordar do marco que assinala a mudança, como é o caso de Crutzen \& Stoermer (2000), que propõem a Revolução Industrial (1800) como início do Antropoceno.

Recentemente, Wilkinson (2005) fez cálculos estimativos da ação do homem no planeta e, comparando-os com a dos agentes naturais, chegou à conclusão de que a humanidade, atualmente, movimenta cerca de 10 vezes mais materiais naturais, do que a soma de todos os materiais mobilizados pelos processos naturais que operam no planeta. Seus cálculos levaram-no a identificar a última parte do primeiro milênio da era cristã como o momento em que o homem se tornou o principal agente geológico da Terra, não propondo, entretanto, uma nova época geológica.

Segundo Brown (1971), em concordância com TerStepanian (1988), podem-se apontar três instrumentos significativos para o homem em seu processo de transformação da natureza: o arado, a pá e a pólvora.

Do arado primitivo originou-se uma sucessão de meios melhorados de revolver a terra, o trator de três ou quatro lâminas, todos destinados a morder mais fundo a terra. Das pás que cavam fossos aos bulldozers, pás mecânicas e escavadeiras. A pólvora conduziu à dinamite, à bomba arrasa quarteirão e à explosão nuclear muito mais poluidora debaixo da terra (Brown 1971).

Destaca-se o arado, instrumento participante da revolução agrícola iniciada há dez mil anos, que marca definitivamente o início do papel do homem como agente geológico (Ter-Stepanian 1988). A necessidade crescente de comida impulsionou esse agente a intensos processos de transformação do meio ambiente, seja nos campos, nos cultivos, seja nas cidades, com a transformação mais intensa da paisagem natural em paisagem cultural. Entre o campo e a cidade, a interligação por estradas alterou o comportamento das águas, tornando-se canais para as águas das “chuvas, passando a fazer parte da natureza dos estreitos vales e ravinas” (Brown 1988). Da mesma forma, os reservatórios construídos com a finalidade de produção de energia elétrica e abastecimento passaram a integrar a natureza, como lagos.

Entretanto, é nas áreas urbanas que o meio ambiente foi mais profundamente modificado, em relação ao original. Nele, não só a cobertura vegetal é eliminada ou extremamente reduzida, como o meio físico é alterado, constituindo-se novos terrenos, seja por escavações, por aterros ou por contaminação.

Atualmente, ocorrem com maior frequência as ocupações urbanas sem planejamento. Como relata
Almeida \& Freitas (1996), “a concentração urbana ocorre em velocidade superior à implantação de infraestruturas”, provocando problemas no meio físico, como erosões, escorregamentos, etc.

Dentro deste contexto, uma abordagem indispensável para compreender os processos instalados numa certa região é a análise da história do uso da terra. Segundo Oliveira et al. (2007), o mapa de uso da terra de uma dada região é normalmente considerado como uma informação secundária em relação aos demais estudos geoambientais. Entretanto, estes autores afirmam que os mapas de uso da terra devem ser valorizados nas questões ambientais, pois permitem compreender os processos geológicos atuais, que resultam da ação do homem enquanto agente transformador do meio ambiente.

As variações do metabolismo primário do meio natural, segundo Ab’Saber (1969), caminham para a irreversibilidade de sua capacidade de regeneração frente às ações do agente geológico, afastando cada vez mais o meio ambiente dessa condição de meio natural.

Os depósitos tecnogênicos podem ser testemunhos dessas transformações, portanto indicadores para a compreensão da ação geológica do homem em várias áreas intensamente modificadas. Bertê (2001) define um depósito tecnogênico como: "O testemunho material da atividade humana que, ao se apropriar da natureza através de suas relações de produção e do emprego de uma técnica que reflete um momento histórico específico do seu nível de desenvolvimento, acaba por produzir modificações na fisiografia e fisiologia das paisagens".

São vários os fatores que contribuem para a criação de um depósito tecnogênico, como descrito por Silva (2012), “criação, indução, intensificação ou modificação da erosão e da carga sedimentar correlativa, escorregamentos em geral, infiltração e escoamento, drenagem pluvial e fluvial, taxas de sedimentação". Tais fatores, aliados ao crescimento populacional e à falta de compreensão do comportamento do meio ambiente, tornam atual a afirmação de Lyell (1830 apud Rossato \& Suertegaray 2000), de que "os processos passados não são visíveis, somente seus efeitos".

\section{Área objeto de estudo}

A área objeto da pesquisa, com 16,2 km², situa-se no município de Guarulhos, que possui área de $320 \mathrm{~km}^{2}$, na Área de Proteção Ambiental Cabuçu - Tanque Grande cuja área total é de 32,2 $\mathrm{km}^{2}$. Está situada no entorno do Núcleo Cabuçu $\left(26 \mathrm{~km}^{2}\right)$ do Parque Estadual da Cantareira - PEC $\left(80 \mathrm{~km}^{2}\right)$. Guarulhos integra a Região Metropolitana de São Paulo (RMSP) a qual abrange 39 municípios, ocupando uma área de cerca de $8.000 \mathrm{~km}^{2}$. A figura 1 apresenta a localização da área em estudo no município de Guarulhos e na RMSP. 


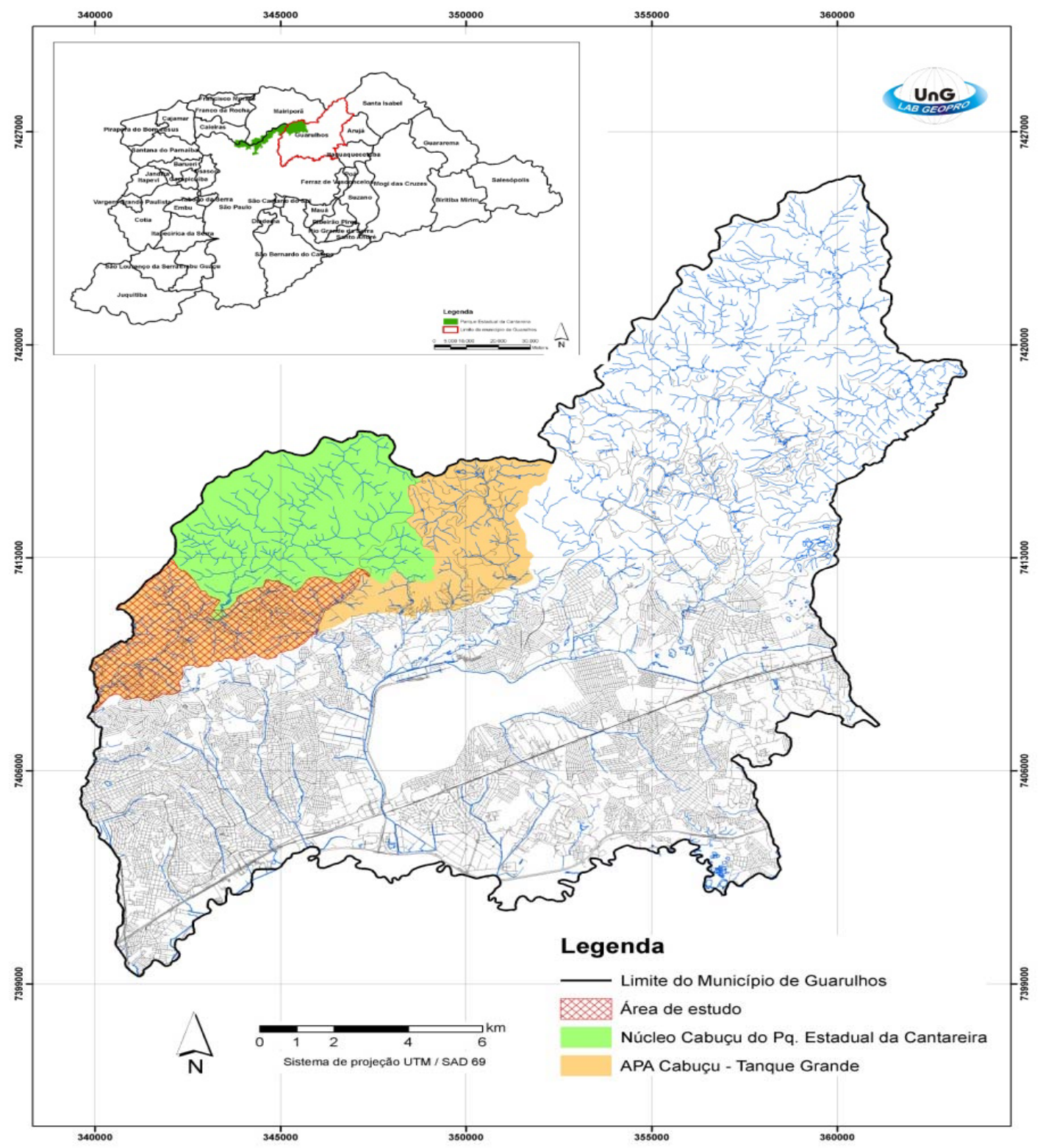

Figura 1: Mapa de localização da área de estudo no município de Guarulhos e na RMSP

Guarulhos, com 453 anos, é hoje o segundo maior município paulista em população, estimada em 1.221.979 habitantes (IBGE 2010). Suas planícies, morros e morrotes têm sido mondados, ao longo do tempo, a favor das ocupações, nem sempre ordenadas.

Dentro do contexto rodoviário, o município possui três grandes rodovias - a Fernão Dias, a Presidente Dutra e rodovia Ayrton Senna - o que facilita a concentração de indústrias. No polo industrial de Cumbica, há aproximadamente 4.266 indústrias (Guarulhos 2011). No ano de 2013, foram iniciadas as obras de implantação do Rodoanel Mario Covas Trecho Norte, cujo traçado atravessa a área objeto da pesquisa.

O clima da área é descrito por Andrade (1999) como mesotérmico brando úmido, apresentando a temperatura mais baixa no mês de junho, com média de $16,6^{\circ} \mathrm{C}$. Os demais meses apresentam média de $20,9^{\circ} \mathrm{C}$, segundo Monteiro (1973 apud Andrade 1999). A pluviosidade média anual da região é de aproximadamente $1.500 \mathrm{~mm}$, conforme medidas da Estação Agroclimatologia UNG/INMET no período 1985-2008, conforme Andrade (2009).

De acordo com Oliveira (2008), predominam, no substrato cristalino da região do Cabuçu, rochas metassedimentares e rochas metavulcânicas básicas, ocorrendo em menores áreas rochas granitoides (Oliveira et al. 2009).

A região localiza-se no Planalto e Serra da Mantiqueira, unidade geomorfológica do Cinturão Orográfico do Atlântico, de acordo com Ross \& Moroz (1997). Como predominância de relevo, Andrade (2009) destaca um sistema de morros e montanhas (entre 800 e $1.100 \mathrm{~m}$ ), em menor proporção os morrotes paralelos (abaixo de $800 \mathrm{~m}$ ) e, de forma muito restrita, os morros e morrotes (entre 800 e $900 \mathrm{~m}$ ), e as planícies aluviais (predominando abaixo de $800 \mathrm{~m}$ ). 
Antropoceno - Tecnógeno

Inserida na faixa de domínio da Floresta Ombrófila Densa Montana, cujos gradientes altitudinais vão de 500 a 1.500 metros, sua formação detém características de regiões tropicais.

\section{Materiais e métodos}

A abordagem adotada é a que considera o meio físico do ponto de vista do Tecnógeno (Ter-Stepanian 1988), ou abordagem geotecnogênica (Oliveira 1995); ou seja, considera o homem como agente geológico, o que implicou em pesquisar a história local, traduzida em mapas.

\section{Etapas da pesquisa}

As principais etapas da pesquisa são a seguir apresentadas.

\section{Etapa 1 - Atividades Preliminares}

As atividades preliminares contemplaram a atualização do conhecimento disponível sobre a área do ponto de vista das características físicas e da história da ocupação, ou seja, levantamentos da bibliografia e de dados disponíveis.

O levantamento de dados foi realizado em órgãos públicos, como a prefeitura de Guarulhos através de suas Secretarias de Meio Ambiente, Cultura, Desenvolvimento Urbano e Departamento de Informática e Tecnologia; com historiadores de Guarulhos; nos Arquivos Históricos Municipal e Estadual; no Instituto Florestal e Fundação Florestal, e no Laboratório de Geoprocessamento da UNG Quadro 1: Levantamentos aerofotogramétricos e coberturas por satélite disponíveis para a área de estudo

\begin{tabular}{lccl}
\hline $\begin{array}{c}\text { Levantamento Aerofotogramétrico e } \\
\text { Cobertura por Satélite }\end{array}$ & Ano & Escala / Resolução & Instituição \\
\hline Levantamento Aerofotogramétrico & 1962 & $1: 25.000$ & IAC - Instituto Agronômico de Campinas \\
Levantamento Aerofotogramétrico & 1970 & $1: 20.000$ & EMPLASA \\
Levantamento Aerofotogramétrico & $1980 / 81$ & $1: 35.000$ & ELETROPAULO, SABESP, EMPLASA \\
Levantamento Aerofotogramétrico & $1984 / 86$ & $1: 10.000$ & ELETROPAULO, SABESP, EMPLASA \\
Levantamento Aerofotogramétrico & $1993 / 94$ & $1: 5.000$ & PMG - Prefeitura Municipal de Guarulhos \\
Levantamento Aerofotogramétrico & 2000 & $1: 5.000$ & PMG - Prefeitura Municipal de Guarulhos \\
Satélite IKONOS & 2007 & $100 \mathrm{~cm}$ & UnG - Universidade Guarulhos \\
\hline
\end{tabular}

Tais levantamentos possibilitaram a elaboração do mapa-síntese dos fatos mais significativos nas alterações do meio físico da região, considerando-se as principais classes de uso da terra definidas: vegetação, agricultura e ocupação urbana.

\section{Etapa 4 - Mapeamento Geotecnogênico}

O mapa do Tecnógeno foi elaborado com base no mapa de uso atual da terra, traduzido em termos de abordagem geotecnogênica, apresentando as alterações ocorridas no meio físico, ou seja, os registros tecnogênicos por tipos de ocupação, escavação, aterro ou intervenção mista.

Com esta finalidade foram usadas as classificações de depósitos tecnogênicos apresentadas nos quadros 2 a 4, segundo Oliveira (1990), Fanning \& Fanning (1989 apud Pellogia1998) e do Serviço Geológico Britânico (Price et al. 2011).
LabGeopro/UNG. Além disso, foram utilizados dados de entrevistas com os moradores mais antigos da área objeto de estudo, realizadas pelo Ponto de Cultura Chico Mendes/Cabuçu, em sua Oficina de Resgate Histórico do Cabuçu.

\section{Etapa 2 - Caracterização do Meio Físico}

A caracterização do meio físico da área objeto de estudo foi realizada com base nos levantamentos bibliográficos e em compilação de dados disponíveis no Laboratório de Geoprocessamento da UNG LabGeopro/UNG, especialmente nos projetos desenvolvidos com o apoio da FAPESP (Oliveira et al. 2005, 2009), e na pesquisa de doutorado de Andrade (2009).

\section{Etapa 3 - História da Região}

Com base na etapa 1, foi elaborada a história da área objeto de estudo, desde os primeiros fatos até os dias atuais, com vistas a elaborar mapas do cenário evolutivo desta ocupação, juntamente com o mapa de toponímia e o diagrama temporal, com destaque para os fatos notáveis que ocorreram no Brasil, Guarulhos e na região do Cabuçu.

Com base nas interpretações das fotos aéreas e imagens de satélite, foram elaborados os mapas de uso da terra da área. Para a região estão disponíveis até o momento os levantamentos de sensoriamento remoto apresentados no quadro 1 .

\section{História da região do Cabuçu}

Com o intuito de aprofundar o conhecimento das transformações ambientais, com base na abordagem geotecnogênica, foram elaborados os cenários sucessivos desde as primeiras intervenções de que se tem conhecimento, até os dias atuais, fundamentandose no estudo da história da região e nos mapas de uso da terra gerados por interpretação de fotos aéreas e imagens de satélite.

A transformação da paisagem, iniciada no final do século XIX, foi seriada em ciclos decadais, desde a primeira década de 1850 até 2010, com desenhos que ilustram o cenário histórico em transformação.

A década de 1850 revela os primeiros indícios de ocupação, que vêm a se expandir até hoje, com a construção da capela Bom Jesus da Cabeça e os possíveis caminhos de acesso, que foram reconstituídos conforme os vestígios atuais. A capela foi construída na área da antiga Fazenda Cabuçu, de propriedade da Sra. Joaquina Fortes. Segundo Herling (2002), esta 
pertencia à população neo-europeia que, por quase quatro séculos, explorou os recursos florestais locais, inclusive do que viria a ser a reserva da Cantareira e o Parque Estadual da Cantareira.

Quadro 2: Classificação dos depósitos tecnogênicos (Oliveira 1990)

\begin{tabular}{ll}
\hline $\begin{array}{l}\text { Depósitos } \\
\text { tecnogênicos }\end{array}$ & \multicolumn{2}{c}{ Descrição } \\
\hline Construídos & $\begin{array}{l}\text { Resultantes da ação humana direta, como } \\
\text { aterros sanitários. }\end{array}$ \\
Induzidos & $\begin{array}{l}\text { Resultantes de processos naturais modificados, } \\
\text { como depósitos de assoreamento de }\end{array}$ \\
& $\begin{array}{l}\text { reservatórios. } \\
\text { Modificados } \\
\text { mas alterados, como solos poluídos. }\end{array}$ \\
\hline
\end{tabular}

Quadro 3: Classificação de materiais de depósitos tecnogênicos construídos, elaborada com base em Fanning \& Fanning (1989, apud Pellogia 1998)

\begin{tabular}{|c|c|}
\hline $\begin{array}{l}\text { Classes de materiais de } \\
\text { depósitos tecnogênicos }\end{array}$ & Descrição \\
\hline Materiais Úrbicos & $\begin{array}{l}\text { Depósitos de artefatos manufaturados } \\
\text { pelo homem, como tijolos, vidros, } \\
\text { concreto, pregos, detritos de demolição } \\
\text { de edifícios. }\end{array}$ \\
\hline Materiais Gárbicos & $\begin{array}{l}\text { Depósitos de material detrítico como } \\
\text { lixo orgânico, de origem humana, } \\
\text { muito ricos em matéria orgânica para } \\
\text { gerar metano em condições } \\
\text { anaeróbicas. }\end{array}$ \\
\hline Materiais Espólicos & $\begin{array}{l}\text { Depósitos de materiais terrosos } \\
\text { escavados e redepositados por } \\
\text { operações de terraplenagem e outras } \\
\text { obras civis, incluindo assoreamentos } \\
\text { induzidos. }\end{array}$ \\
\hline Materiais Dragados & $\begin{array}{l}\text { Depósitos de materiais terrosos } \\
\text { provenientes da dragagem de cursos } \\
\text { d’água e comumente depositados em } \\
\text { cotas topográficas superiores às da } \\
\text { planície aluvial. }\end{array}$ \\
\hline
\end{tabular}

Quadro 4: Classes de terrenos artificiais dos mapas e dos modelos geológicos tridimensionais produzidos pela British Geological Survey. Modificado de Ford et al. (2010 apud Price et al. 2011)

\begin{tabular}{ll}
\hline $\begin{array}{l}\text { Classes } \\
\text { terrenos } \\
\text { artificiais }\end{array}$ & \multicolumn{1}{c}{ Descrição } \\
\hline $\begin{array}{l}\text { Terreno produzido } \\
\text { (made ground) }\end{array}$ & $\begin{array}{l}\text { Áreas onde o material foi disposto pelo } \\
\text { homem sobre uma superfície de terreno } \\
\text { natural preexistente. }\end{array}$ \\
$\begin{array}{l}\text { Terreno escavado } \\
\text { (worked ground) }\end{array}$ & $\begin{array}{l}\text { Áreas onde uma superfície preexistente de } \\
\text { superfície de terreno foi escavada pelo } \\
\text { homem. }\end{array}$ \\
$\begin{array}{l}\text { Terreno preenchido } \\
\text { (infilled ground) }\end{array}$ & $\begin{array}{l}\text { Áreas onde uma superfície preexistente de } \\
\text { terreno foi escavada (terreno escavado) e } \\
\text { subsequentemente parcial ou totalmente } \\
\text { preenchida (terreno produzido) pelo homem. }\end{array}$ \\
$\begin{array}{l}\text { Terreno perturbado } \\
\text { (disturbed ground) }\end{array}$ & $\begin{array}{l}\text { Áreas de superfície próximas a minerações } \\
\text { onde foram realizadas escavações (terreno } \\
\text { escavado), áreas de subsidência causadas } \\
\text { pelas escavações e bota-foras (made } \\
\text { ground), associadas entre si de forma }\end{array}$ \\
$\begin{array}{l}\text { complexa } \\
\text { transformado } \\
\text { landscape ground) }\end{array}$ & $\begin{array}{l}\text { Áreas onde a superfície do terreno foi } \\
\text { extensamente remodelada, } \\
\text { produzido, escavado ou perturbado. }\end{array}$ \\
\hline
\end{tabular}

Este processo de transformação da paisagem pode ser descrito segundo vários aspectos, apresentados a seguir.

Em relação à água, o Cabuçu iniciou sua vida contemporânea com o abastecimento de água para São Paulo, de 1900 a 1973. Após a desativação dessa atividade, durante quase 30 anos, foi reativado em 2001 e hoje abastece a população de Guarulhos. Essa trajetória revela uma política de uso dos recursos hídricos, desde os empreendimentos pioneiros realizados no início do século XX, à adoção de grandes empreendimentos nos anos de 1970, com o Sistema Cantareira da Companhia Metropolitana de Água de São Paulo (COMASP), atual Companhia de Saneamento Básico de São Paulo (SABESP) e, por fim, a revalorização dos recursos hídricos de pequeno porte no século XXI, como Serviço Autônomo de Água e Esgoto (SAAE).

Na agricultura, o início pode ter sido uma grande fazenda em 1850 relatada por Oliveira et al. (2007), seguida de vários sítios produtores de chuchu, quando Guarulhos chegou a ser o terceiro maior produtor do estado de São Paulo, em 1970. Hoje, esta é uma atividade em extinção.

As cavas realizadas para a extração de argila nas olarias contribuíram em um dos primeiros ciclos econômicos, durando cerca de 70 anos, (de 1910 a 1980), quando desapareceram e foram sendo substituídas por pequenas fábricas de blocos de cimento.

Quanto à disposição dos resíduos, a região do Cabuçu recebeu, acompanhando o crescimento da cidade de Guarulhos durante 20 anos, de 1980 a 1999, todo lixo produzido na cidade, sem nenhuma forma de tratamento. Entre 1999 e 2001, passou para aterro controlado em uma área adjacente, e em 2002 começou a operar como aterro sanitário, situação que perdura até os dias atuais. Este processo vem sendo acompanhado pela instalação de pequenos empreendimentos de reciclagem.

A população do Cabuçu permaneceu estável, até o ano de 1981. Em seguida, houve intensa ocupação por imigrantes, que atingiu seu auge com as invasões em 1997, descaracterizando a cultura local que começava a se formar. A região adquiriu características de bairrodormitório. Entretanto, a criação da APA Cabuçu Tanque Grande, em 2010, e as iniciativas locais como a criação da ONG Associação Cultural e Ambiental Chico Mendes, vêm estimulando os moradores a lutar por um melhor meio socioambiental na região.

Toda essa expansão catalisou a instalação de grandes empreendimentos, como o Hotel e Centro de Convenções Santa Mônica, o Instituto Manoel Moreira Giesteira de Promoção Humana e a Fazenda Três Marias, que foi utilizada como área de empréstimos e disposição de resíduos. A indústria também se instalou na região com a Empresa Higie Topp de Produtos Higiênicos e a Beneficiadora de Legumes Batista.

A construção, iniciada no ano de 2013, do Trecho Norte do Rodoanel Mario Covas, cujo traçado se 
estende longitudinalmente sobre o território da APA, constitui uma nova e intensa transformação da paisagem.

Nessa última década, o Cabuçu ganhou mais dois loteamentos, o Jardim Santa Mônica e a Vila Julieta, que se uniram aos já existentes Morro do Sabão, Jardim Siqueira Bueno, Jardim Monte Alto, Jardim dos
Cardosos, Chácaras Cabuçu, Recreio São Jorge e Novo Recreio, compondo o cenário urbano atual da região do Cabuçu.

Com base no levantamento histórico e no levantamento aerofotogramétrico de 1962, foi possível elaborar o cenário da década de 1960, apresentado na figura 2.

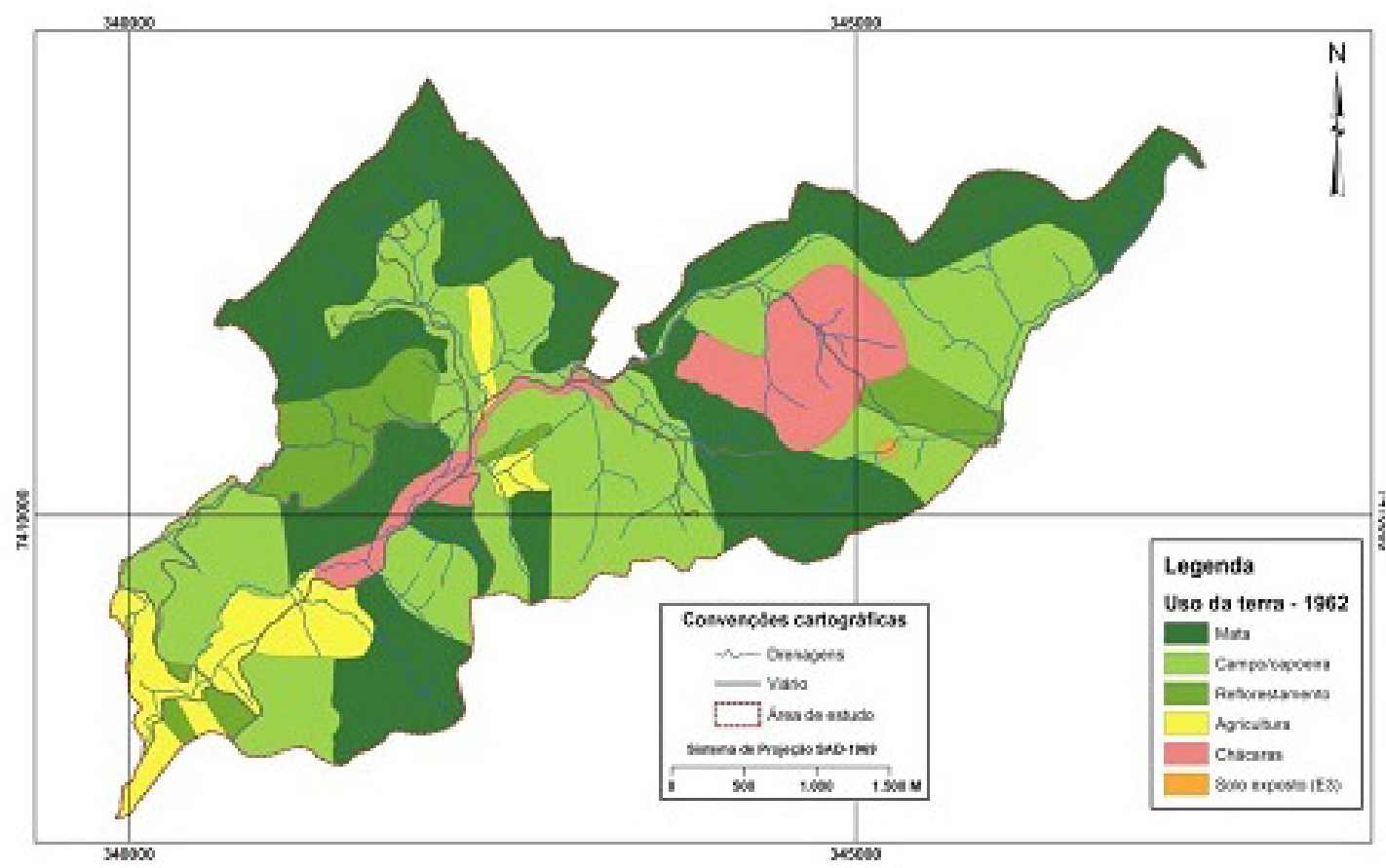

Figura 2: Mapa do uso da terra do Cabuçu (Guarulhos, SP) referente a 1962

Por meio de interpretações de fotos aéreas e imagens de satélite, foram elaborados os mapas da evolução do uso da terra do Cabuçu referentes às décadas de 1960 a 2007, ilustrados na figura 3, cuja legenda encontra-se no quadro 5.

O quadro 6 apresenta as subclasses dos usos urbanos e dos solos expostos.

As áreas de ocorrência de cada classe de uso da terra foram quantificadas, sendo a evolução das principais classes visualizada na figura 4. Nesta, foi plotada a evolução da população do Cabuçu, que em 1991 apresentava 28.709 habitantes, em 2000, 59.675 habitantes, e em 2010 atingiu 73.076 habitantes (IBGE 2010).

A região revelou não possuir vocação para a agricultura senão em áreas restritas de fundo de vale, tendo sofrido redução drástica ao longo dos anos. Restaram também pequenas áreas ocupadas por chácaras. As áreas de solo exposto destinadas a empréstimos de terra (E3) tiveram aumento em comparação com as áreas destinadas a resíduos (E1) e empreendimentos (E2), que se mantiveram constantes. A análise dos gráficos da Figura 5 mostra como fato mais notável o avanço das ocupações urbanas na região, que tiveram seu auge em 1986, com a classe de uso urbano inicial - lotes (UL1), conforme legenda exposta no quadro 5.
Quadro 5: Legenda dos mapas de classes de uso da terra elaborados

\begin{tabular}{|c|c|c|}
\hline Sigla & Nomenclatura & \\
\hline $\mathbf{M}$ & Mata & \\
\hline C & $\begin{array}{l}\text { Campo, Capoeira } \\
\text { e Arbustivas }\end{array}$ & \\
\hline $\mathbf{R}$ & Reflorestamento & \\
\hline A & $\begin{array}{l}\text { Agricultura, } \\
\text { Chácaras e Sítios }\end{array}$ & \\
\hline $\mathbf{H}$ & Chácara & \\
\hline $\begin{array}{l}\text { UQ } \\
\text { (Urbano }\end{array}$ & UQ1 & $\begin{array}{ll}\text { Início } & \text { de } \\
\text { implantacão } & \end{array}$ \\
\hline quadra & UQ2 & Em consolidação \\
\hline terraplanada) & UQ3 & $\begin{array}{l}\text { Consolidada com } \\
\text { pavimentação }\end{array}$ \\
\hline $\begin{array}{l}\text { UL } \\
\text { (Urbano por lote }\end{array}$ & UL1 & $\begin{array}{ll}\text { Início } & \text { de } \\
\text { implantação } & \end{array}$ \\
\hline - manual) & UL2 & Em consolidação \\
\hline & UL3 & $\begin{array}{l}\text { Consolidada com } \\
\text { pavimentação }\end{array}$ \\
\hline $\begin{array}{l}\text { E } \\
\text { (Área de Solo }\end{array}$ & E1 & $\begin{array}{l}\text { Disposição de } \\
\text { resíduos }\end{array}$ \\
\hline exposto) & E2 & $\begin{array}{l}\text { Área destinada a } \\
\text { empreendimentos }\end{array}$ \\
\hline & E3 & $\begin{array}{l}\text { Destinada } \\
\text { empréstimos }\end{array}$ \\
\hline $\mathbf{O}$ & Olaria & \\
\hline $\mathbf{L}$ & Lago & \\
\hline $\mathbf{X}$ & Lixão & \\
\hline
\end{tabular}



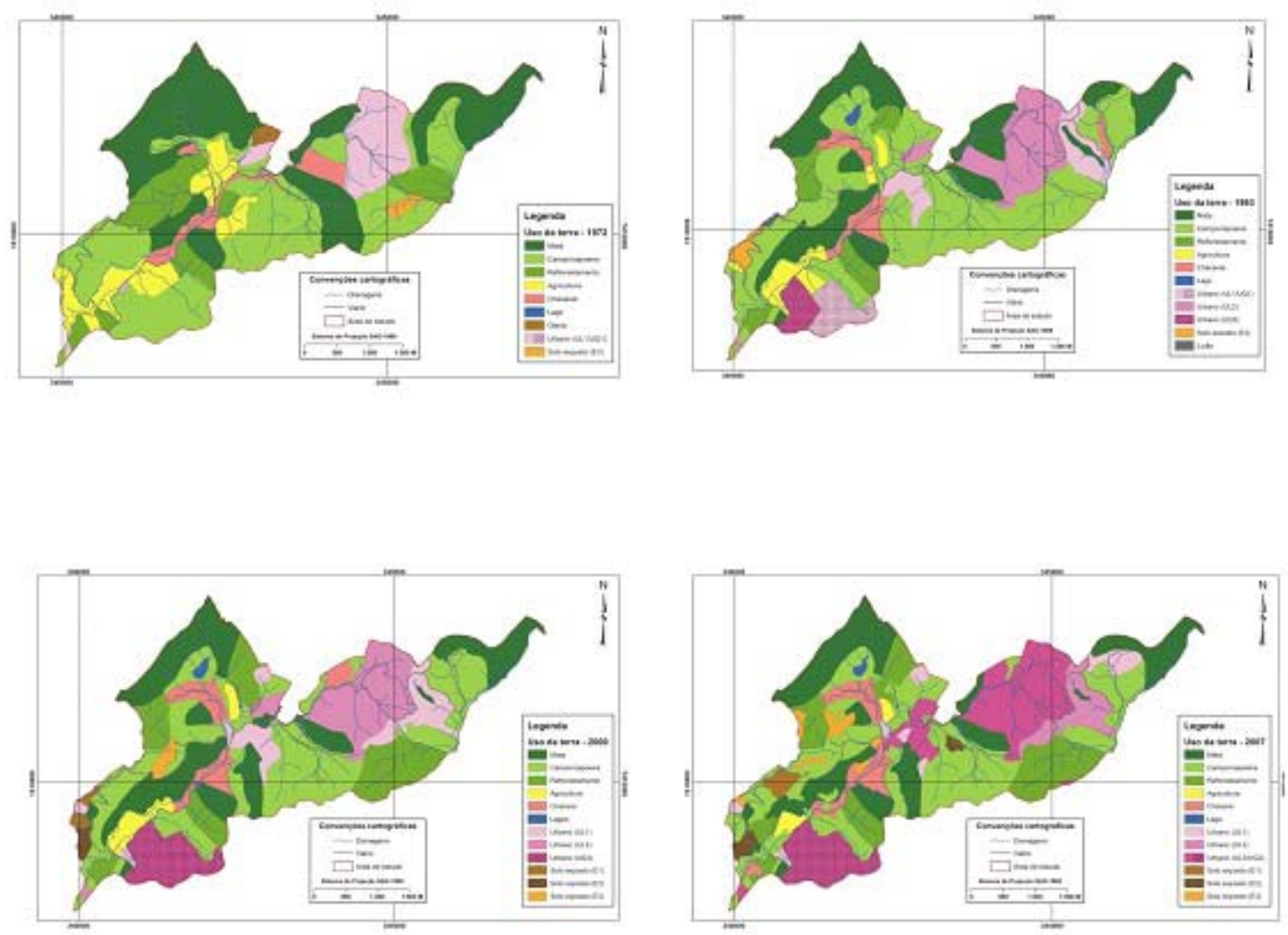

Figura 3: Mapas de uso da terra do Cabuçu (Guarulhos, SP) nos anos de 1970, 1990, 2000 e 2007

Quadro 6: Classes de uso urbano da terra conforme formas de ocupação

\begin{tabular}{|c|c|c|c|c|}
\hline Siglas & Ocupação & Terraplenagem & Cobertura Vegetal & Loteamentos \\
\hline UQ & $\begin{array}{l}\text { Regular } \\
\text { (Aprovada na PMG) } \\
\text { Regular } \\
\text { (Aprovada na PMG) }\end{array}$ & $\begin{array}{l}\text { Mecanizada - } \\
\text { generalizada por quadras }\end{array}$ & $\begin{array}{l}\text { Supressão total da vegetação, } \\
\text { exposição do solo }\end{array}$ & $\begin{array}{l}\text { Jardim Cambará e Parque } \\
\text { Continental III } \\
\text { Chácaras Cabuçu, Jd. Monte } \\
\text { Alto, Jd. Siqueira Bueno, Morro } \\
\text { do Sabão, Recreio São Jorge e } \\
\text { Jd. Santa Mônica }\end{array}$ \\
\hline E1 & $\begin{array}{l}\text { Irregular } \\
\text { (Não aprovada na PMG) } \\
\text { Solo Exposto } \\
\text { (Disposição de Resíduos) }\end{array}$ & & & $\begin{array}{l}\text { Novo Recreio, Vila Julieta e Jd. } \\
\text { Cardoso } \\
\text { Fazenda Três Marias }\end{array}$ \\
\hline E2 & $\begin{array}{l}\text { Solo Exposto } \\
\text { (Empreendimento Particular) } \\
\text { Solo Exposto } \\
\text { (Área de Empréstimos) }\end{array}$ & $\begin{array}{l}\text { Mecanizada - } \\
\text { generalizada }\end{array}$ & $\begin{array}{l}\text { Supressão total } \\
\text { da vegetação, exposição do } \\
\text { solo }\end{array}$ & $\begin{array}{l}\text { Instituto Manoel Giesteira } \\
\text { Propriedade Zariff }\end{array}$ \\
\hline
\end{tabular}

- UQ: Loteamento regular com terraplanagem mecanizada e generalizada por quadra.

- UL: Loteamentos regulares e irregulares com terraplanagem manual por lote.

PMG: Prefeitura Municipal de Guarulhos. 


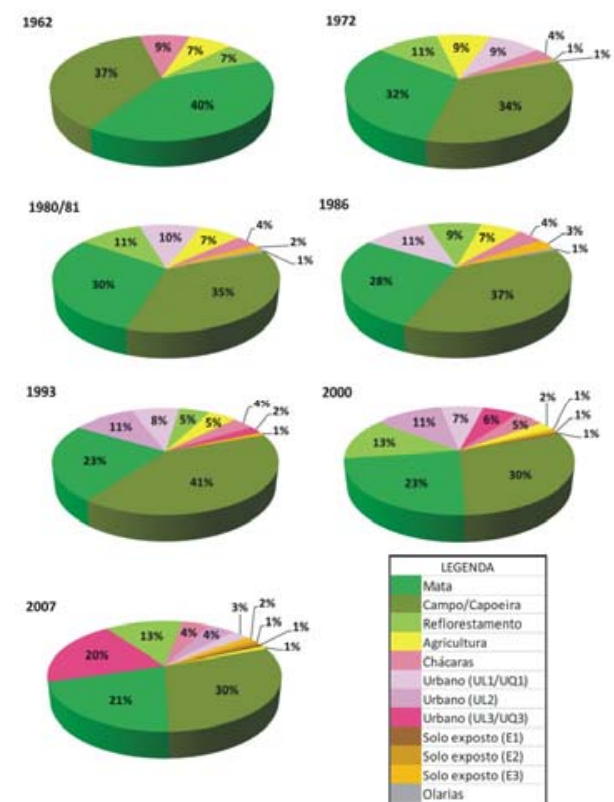

Figura 4: Gráfico de evolução do uso da terra

Hoje esta classe apresenta a menor área de ocupação, devido ao fato de ter se transformado em áreas de estágio urbano em consolidação - lotes (UL2) e consolidadas (UL3). Estas áreas, que aumentaram nos anos de 1993 e 2000, apresentaram queda em 2007. Já o estágio urbano consolidado - lotes/quadra (UL3 e UQ3), que em 2000 apresentava 6\% das áreas, teve aumento de quase $14 \%$ em apenas sete anos.

\section{Analise geotecnogênica}

Conforme apresentado no item 2, a análise geotecnogênica fundamenta-se no princípio de que o homem é o agente geológico predominante do ambiente atual.

Quadro 7: Legenda do Mapa de Paisagens do Cabuçu (Guarulhos, SP)
No sentido de expressar o processo geotecnogênico de transformação da paisagem, foram elaborados dois mapas da região objeto de estudo.

O primeiro, apresentado na figura 5, constitui o Mapa do Tecnógeno (com legenda explicativa exposta no quadro 7), que revela a transformação da paisagem natural em paisagem biotecnogênica e geotecnogênica. A análise da figura 6 revela que há uma grande mancha geotecnogênica a leste (Chácaras Cabuçu, Recreio São Jorge e Novo Recreio), concentrando as mais fortes transformações pelo uso urbano dos terrenos e onde se destaca a presença mais acentuada de áreas de risco a escorregamentos (Gomes 2008). As demais paisagens geotecnogênicas encontram-se mais disseminadas na região.

\begin{tabular}{|c|c|c|c|c|c|c|c|}
\hline $\begin{array}{l}\text { Unidade ou } \\
\text { Paisagem }\end{array}$ & $\begin{array}{c}\text { Ações } \\
\text { Antrópicas }\end{array}$ & $\begin{array}{c}\text { Intensidade da } \\
\text { Ação } \\
\text { Tecnogênica } \\
\text { no Meio Físico } \\
\end{array}$ & $\begin{array}{c}\text { Alteração } \\
\text { Tecnogênica }\end{array}$ & $\begin{array}{l}\text { Modificações Físicas } \\
\text { Predominantes do Solo }\end{array}$ & $\begin{array}{c}\text { Processos } \\
\text { Geotecnogênicos } \\
\text { Predominantes } \\
\text { Mais Expressivos }\end{array}$ & $\begin{array}{l}\text { Depósitos } \\
\text { Correlatos }\end{array}$ & $\begin{array}{l}\text { Substr } \\
\text { atos } \\
\text { Geológ } \\
\text { icos }\end{array}$ \\
\hline Natural & $\begin{array}{l}\text { Preservação, } \\
\text { Abandono }\end{array}$ & $\begin{array}{c}\text { Nula ou Muito } \\
\text { Baixa }\end{array}$ & $\begin{array}{c}\text { Com ou sem } \\
\text { alteração } \\
\text { significativa } \\
\text { da biota. } \\
\text { Solo natural } \\
\text { não } \\
\text { modificado } \\
\text { diretamente. }\end{array}$ & $\begin{array}{c}\text { Não ocorrem ou } \\
\text { encontram-se cicatrizes de } \\
\text { erosão }\end{array}$ & $\begin{array}{l}\text { Não ocorrem ou } \\
\text { encontram-se } \\
\text { cicatrizados }\end{array}$ & $\begin{array}{c}\text { Podem } \\
\text { ocorrer } \\
\text { depósitos } \\
\text { induzidos } \\
\text { antigos }\end{array}$ & $\begin{array}{c}\text { Estávei } \\
\text { s }\end{array}$ \\
\hline $\begin{array}{l}\text { Biotecnôgeni } \\
\text { ca }\end{array}$ & $\begin{array}{l}\text { Silvicultura, } \\
\text { Agricultura e } \\
\text { Pecuária }\end{array}$ & Baixa e Média & $\begin{array}{l}\text { Biota natural } \\
\text { eliminada. } \\
\text { Solo pouco } \\
\text { modificado. }\end{array}$ & Indiretas e induzidas & $\begin{array}{l}\text { Erosão difusa e } \\
\text { linear, } \\
\text { assoreamento }\end{array}$ & Induzidos & $\begin{array}{c}\text { Modifi } \\
\text { cados }\end{array}$ \\
\hline $\begin{array}{l}\text { Geotecnogên } \\
\text { ica }\end{array}$ & $\begin{array}{l}\text { Urbanização, } \\
\text { aterros, } \\
\text { empréstimo } \\
\text { e } \\
\text { infraestrutura } \\
\text { civil }\end{array}$ & Alta & $\begin{array}{l}\text { Biota natural } \\
\text { eliminada. } \\
\text { Solo muito } \\
\text { modificado. }\end{array}$ & $\begin{array}{c}\text { Complexas } \\
\text { - De Subtração (cortes, } \\
\text { cavas, lavras) } \\
\text { - De Adição } \\
\text { (aterros, bota-foras) } \\
\text { - De Modificação } \\
\text { (contaminação) } \\
\text { - Mistas (aterros } \\
\text { sanitários) }\end{array}$ & $\begin{array}{l}\text { Erosão linear, } \\
\text { movimentos de } \\
\text { massa, } \\
\text { assoreamentos, } \\
\text { alagamentos, } \\
\text { inundações e } \\
\text { recalques }\end{array}$ & $\begin{array}{l}\text { Induzidos, } \\
\text { construídos, } \\
\text { remobilizado } \\
\text { s, } \\
\text { contaminado } \\
\text { s }\end{array}$ & $\begin{array}{l}\text { Modifi } \\
\text { cados, } \\
\text { escava } \\
\text { dos }\end{array}$ \\
\hline
\end{tabular}




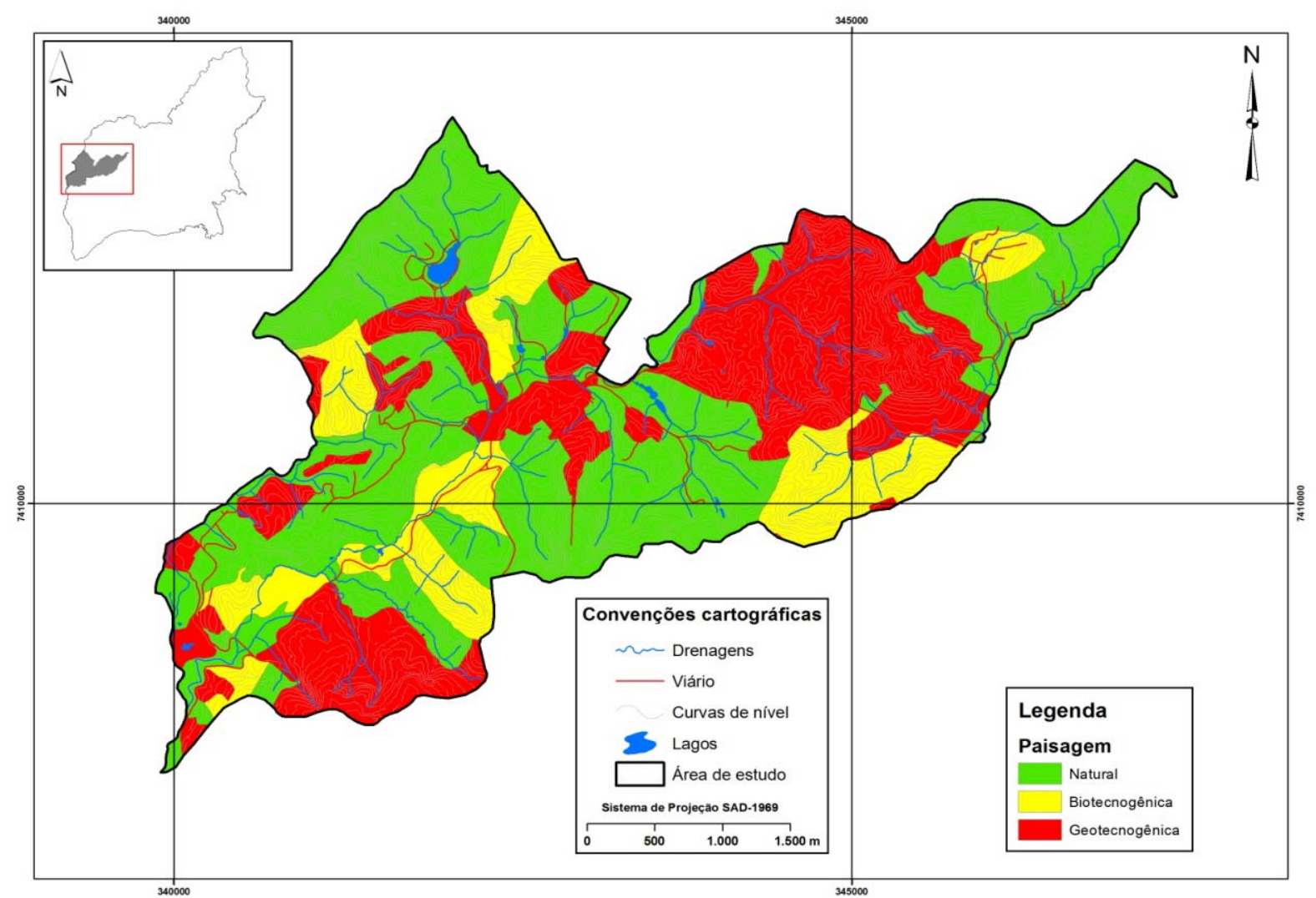

Figura 5: Mapa de Paisagens do Cabuçu (Guarulhos, SP)

O segundo mapa, apresentado na figura 7 , identifica as classes dos terrenos dessa paisagem tecnogênica, cuja legenda explicativa está exposta no quadro 8.

Quadro 8: Classes de uso dos terrenos e depósitos tecnogênicos identificados no Cabuçu (Guarulhos, SP)

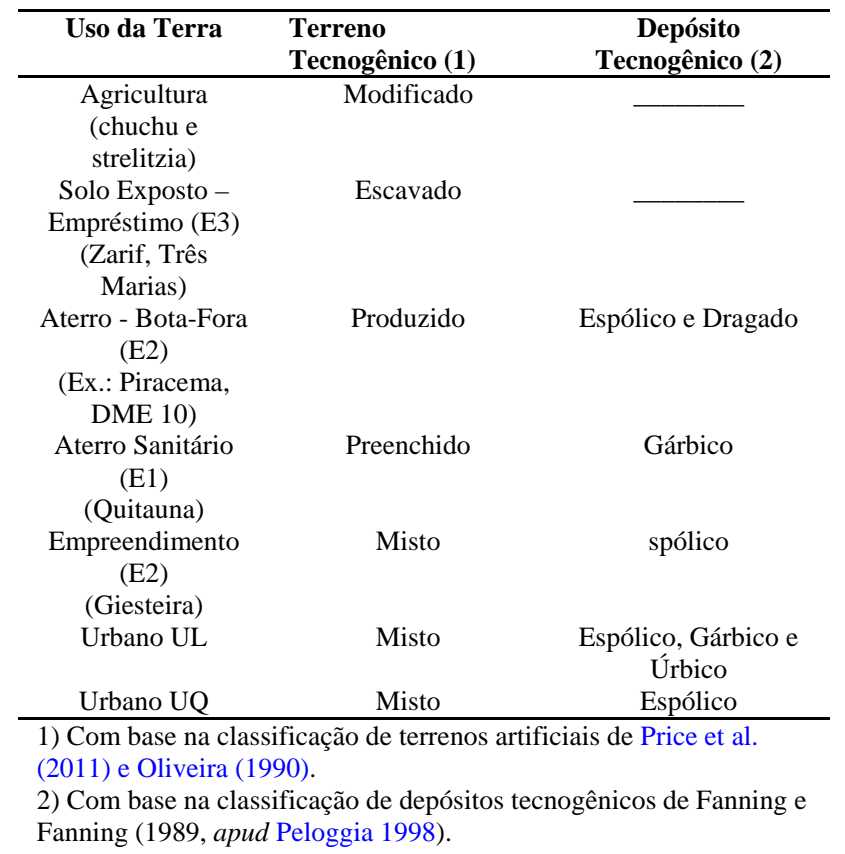

\section{Conclusões}

As transformações antrópicas do meio ambiente, resultando em terrenos alterados por escavações, aterros e contaminações, estão exigindo o desenvolvimento de uma cartografia específica dos novos terrenos.

Esta cartografia geotecnogênica demanda a elaboração de novas legendas, existindo ainda poucos exemplos neste campo no Brasil.

Alguns critérios para este tipo de cartografia ou mapeamento podem ser apontados. A partir do fundamento da abordagem geotecnogênica, é necessário conhecer, além dos principais componentes naturais do meio físico (clima, geologia, geomorfologia e pedologia), o uso da terra, que constitui a manifestação objetiva do homem como agente geológico. Este é o primeiro critério: o conhecimento da história do uso da terra, em detalhes pertinentes ao objeto de mapeamento e à área de estudo.

Os critérios seguintes dependem da escala e objeto do mapeamento geotecnogênico. No caso de mapeamentos regionais, como é o caso do presente trabalho, um segundo critério é realizar uma primeira aproximação ao problema elaborando um mapa de paisagens em que seja possível distinguir diferentes graus de transformação. No presente trabalho a legenda deste mapa foi sintetizada em três categorias; natural, biotecnogênica e geotecnogênica. 


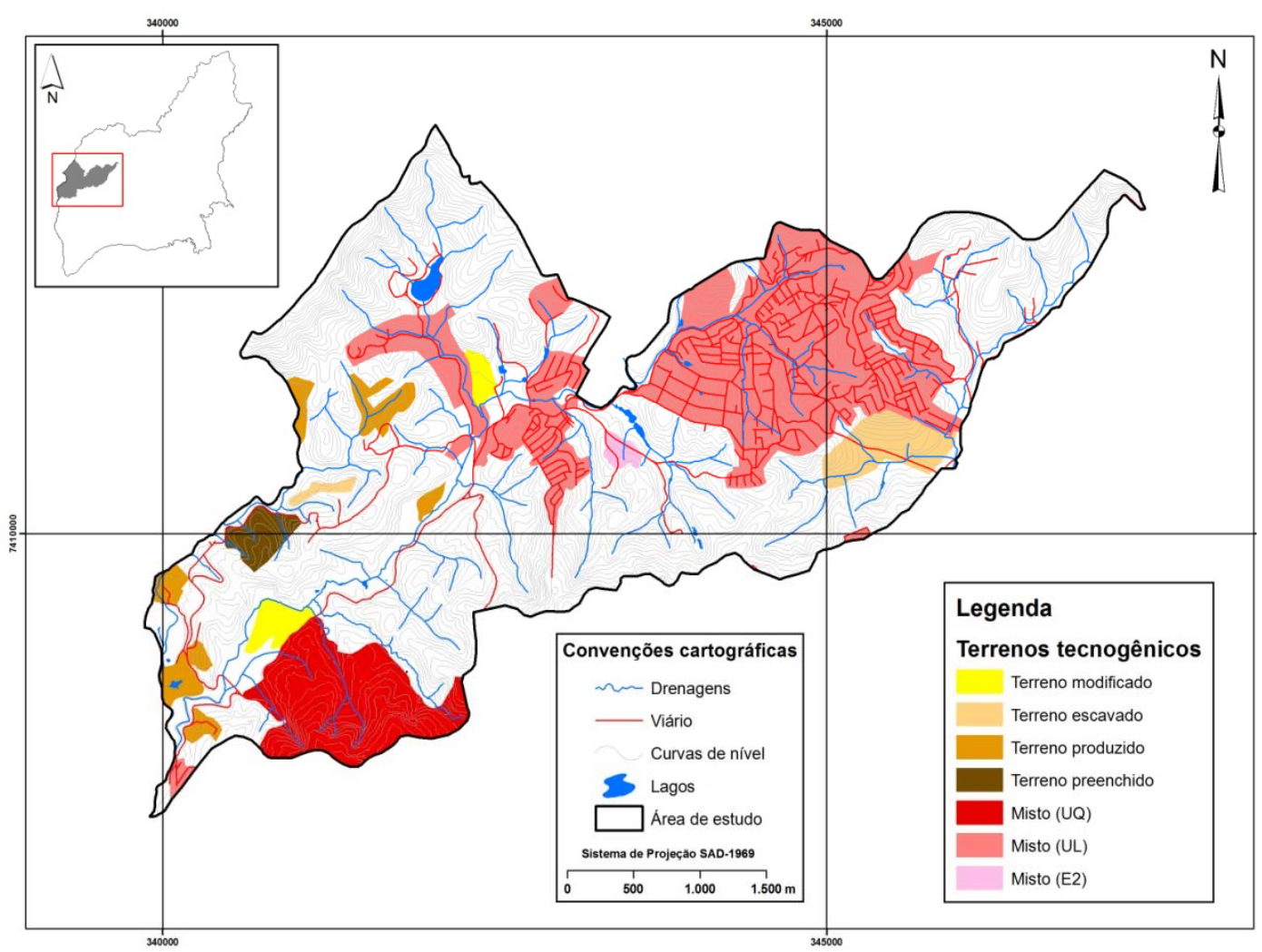

Figura 6: Mapa do Tecnógeno do Cabuçu (Guarulhos, SP)

Um terceiro critério é considerar as legendas elaboradas com base nas classificações disponíveis, procurando adaptá-las às necessidades de mapeamento.

Neste momento em que pesquisadores buscam soluções para a realização de mapeamentos geotecnogênicos, espera-se que o presente trabalho constitua uma efetiva contribuição.

\section{Agradecimentos}

Os autores agradecem a FAPESP pelo apoio à pesquisa com a bolsa de mestrado da primeira autora (Processo N. 2011/16456-8).

\section{Referências}

Ab’Saber A.N. 1969 Um conceito de geomorfologia serviço das pesquisas sobre o quartenário. Instituto de Geografia. Boletim N¹8, Geomorfologia, Universidade de São Paulo, 23 p.

Almeida M.C.J., Freitas C.G.L. 1996 O uso do solo urbano: suas relações com o meio físico e problemas decorrentes. In: Simpósio Brasileiro de Cartografia Geotécnica, 2., 1996. São Carlos (SP). Anais... ABGE, São Carlos p.195-200.

Andrade M.R.M. 1999. Cartografia de aptidão para assentamento urbano do município de Guarulhos/SP. Dissertação de Mestrado Pós-Graduação em Geografia - Faculdade de Filosofia, Letras e Ciências Humanas, Universidade de São Paulo.

Andrade M.R.M. 2009. Planejamento ambiental da APA Cabuçu Tanque Grande Guarulhos - SP. Tese de Doutorado Programa de Pós-Graduação em Geografia Física, Universidade de São Paulo.

Bertê A.M.A. 2001. Depósitos tecnogênicos e planejamento urbano: o aterro sanitário da zona norte de Porto Alegre - RS/Brasil. Dissertação de Mestrado Programa de Pós-Graduação em Geografia, Instituto de Geociências, Universidade Federal do Rio Grande do Sul.

Brown E.H. 1971. O homem modela a terra. 1971. Instituto Brasileiro de Geografia. Boletim Geográfico, N 222. Ano 30. Maio-Junho.
Crutzen P.J., Stoermer E.F. 2000 The Anthopocene. IGBP Newsletter 41:17-18.

Fanning D.J., Fanning M.C.B. 1989. Morphology, genesis and classification. In: Peloggia, A.U.G. O homem e o ambiente geológico. 1998. Xamã 271p.

Gomes G.L.C.C. 2008. Análise geoambiental de áreas de risco a escorregamentos nos loteamentos do Recreio São Jorge e Novo Recreio, município de Guarulhos-SP. 2008. Dissertação de Mestrado Programa de Pós Graduação em Análise Geoambiental Centro de Pesquisa e Extensão - Universidade Guarulhos, 86 p.

Herling T. 2002. A floresta em São Paulo, a cidade na Cantareira: fronteiras em transformação. Tese de Doutorado Programa de Pós-Graduação em Arquitetura Faculdade de Arquitetura e Urbanismo da Universidade de São Paulo.

IBGE - Instituto Brasileiro de Geografia e Estatística. 2010. Dados. <http://www.censo2010.ibge.gov.br/primeiros_dados_divulgado s/index.php>. Acesso em: 10 de agosto de $201 \overline{1}$.

Lovelock J.E. 1988. The Ages of Gaia: a Biography of our living Earth.: W.W. Norton \& Company, New York, 255 p.

Mirandola F.A. 2003 Zoneamento de Risco Geológico na Área da Favela Real Parque, São Paulo. Monografia de Conclusão do Curso de Geologia) - Instituto de Geociências, Universidade de São Paulo.

Oliveira A.M.S. 1990. Depósitos tecnogênicos associados à erosão atual. In: Congresso Brasileiro de Geologia de Engenharia. Salvador. Anais... ABGE. 1:411-415.

Oliveira A.M.S. 1995. A abordagem geotecnogênica: a Geologia de Engenharia no Quinário. In: Bitar, O.Y. (Coord.) Curso de Geologia Aplicada ao Meio Ambiente. Associação Brasileira de Geologia de Engenharia, Instituto de Pesquisas Tecnológicas. São Paulo. p.231-241.

Oliveira A.M.S. 2005. Estudos sobre o Tecnógeno do Brasil. In. Simpósio Brasileiro do Tecnógeno. Associação Brasileira de Estudos do Quaternário, Guarapari (ES), CD-ROM.

Oliveira A.M.S., Andrade M.R.M., Queiroz W., Sato S.E. 2005. Diagnóstico ambiental para o manejo sustentável do Núcleo Cabuçu do Parque Estadual da Cantareira e áreas vizinhas do município de Guarulhos. Laboratório de Geoprocessamento da Universidade de Guarulhos, Guarulhos, 2005.109 p.2 v. Mapas. (Relatório FAPESP - Processo 01/02767-0). 
Antropoceno - Tecnógeno

Oliveira A.M.S., Andrade M.R.M., Queiroz W., Sato S.E. 2007. Construção de legenda para mapa de uso do solo à análise geoambiental do município de Guarulhos, SP. In: Simpósio Brasileiro de Cartografia Geotécnica e Geoambiental, 6, Anais... Uberlândia.

Oliveira A.M.S. (coord.) 2008. Atlas geoambiental da região Cabuçu - Tanque Grande, Guarulhos, SP. Universidade Guarulhos. 47p.

Oliveira A.M.S., Andrade M.R.M., Queiroz W., Sato S.E. 2009. Bases geoambientais para um sistema de Informações ambientais do município de Guarulhos. Laboratório de Geoprocessamento da Universidade de Guarulhos, Guarulhos, 2009. 178p. 4v. Mapas. (Relatório FAPESP - Processo 05/57965-1).

Oliveira E.S. 2007. Guarulhos espaço de muitos povos - conto, canto e encanto com minha história: Noovha America, São Paulo.

Peloggia A.U.G. 1998. O homem e o ambiente geológico. Xamã São Paulo, 271p.

Price S.J. 2011. Humans as major geological and geomorphological agents in the Anthropocene: the significance of artificial ground in Great Britain. The Royal Society. 369:1056-1084.

Ribeiro D.O. 1975. Processo civilizatório. Etapas da evolução sóciocultural em estudos da antropologia da civilização. Civilização Brasileira, Rio de Janeiro, 3. ed. 265p.

Rossato M.S., Suertegaray D.M. 2000. Repensando o tempo da natureza em transformação. Ágora (UNISC), Santa Cruz, 6(2):93-98

Ross J.S., Moroz I.C. 1997. Mapa geomorfológico do Estado de São Paulo. FFLCH-USP/ Laboratório de Cartografia GeotécnicaGeologia Aplicada - IPT/FAPESP - Fundação de Amparo à Pesquisa do Estado de São Paulo, $1^{\circ}$ Ed., p.64.

São Paulo (Estado). 2005. Inventario Florestal da Vegetação Natural do Estado de São Paulo. Secretaria do Meio Ambiente / Instituto Florestal. Ed. Impressa Oficial.

Silva E.C.N. 2012. Formação de depósitos tecnogênicos e relação com o uso e ocupação do solo no perímetro urbano de Presidente Prudente - SP. 2012. Dissertação de Mestrado Programa de PósGraduação em Geografia da Faculdade de Ciências e Tecnologia - Universidade Estadual Paulista.

Silva M. 2013. Impactos ambientais decorrentes da instalação de depósitos tecnogênicos na Ilha de Santa Catarina, SC, Brasil. Dissertação de Mestrado Programa de Pós-Graduação em Geografia da Universidade Federal de Santa Cantarina.

Ter-Stepanian G. 1988. Beginning of the Technogene. Bulletin of the International Association of Engineering Geology. 38:133-142.

Wilkinson B.H. 2005. Human as geologic agents: a deep time perspective. Geology. 33(3):161-164.

Recebido 10 de dezembro de 2013

Aceito 19 de agosto de 2014 